\title{
Hepatocellular carcinoma-targeted effect of configurations and groups of glycyrrhetinic acid by evaluation of its derivative-modified liposomes
}

This article was published in the following Dove Press journal: International Journal of Nanomedicine

\section{Yuqi Sun ${ }^{1,2}$ \\ Chunmei Dai' \\ Meilin Yin' \\ jinghua $\mathrm{Lu}^{\prime}$ \\ Haiyang $\mathrm{Hu}^{2}$ \\ Dawei Chen ${ }^{2}$}

'School of Pharmacy, Jinzhou Medical University, Jinzhou, China; ${ }^{2}$ School of Pharmacy, Shenyang Pharmaceutical University, Shenyang, China
Correspondence: Dawei Chen School of Pharmacy, Shenyang Pharmaceutical University, No 103, Wenhua Road, Shenyang 110016 , China Tel +862423986308

Email syphuchendw@I26.com
Background: There are abundant glycyrrhetinic acid (GA) receptors on the cellular membrane of hepatocytes and hepatocellular carcinoma (HCC) cells. The receptor binding effect might be related to the structure of the guiding molecule. GA exists in two stereoisomers with C3-hydroxyl and C11-carbonyl active groups.

Purpose: The objective of this study was to investigate the relationship between the HCCtargeted effect and the configurations and groups of GA.

Methods and results: Different GA derivatives (18 $\beta$-GA, 18 $\alpha$-GA, 3-acetyl-18 $\beta$-GA [3-Ace-GA] and 11-deoxy-18ß-GA [11-Deo-GA]) were used to investigate the targeting effect of GA's configurations and groups on $\mathrm{HCC}$ cells. The $\mathrm{EC}_{50}$ values of competition to binding sites and the ratio of specific binding in HepG2 cells showed that 18ß-GA and 3-Ace-GA demonstrated significant competitive effect with fluorescein isothiocyanate (FITC)-labeled GA. Then, the GA derivatives were distearoyl-phosphatidylethanolamine (DSPE)-PEGylated. 18ß-GA-, 18 $\alpha$-GA-, 3-Ace-GAand 11-Deo-GA-modified liposomes were prepared and characterized by size, zeta potential, encapsulation efficiency, loading capacity, leakage and membrane stability. Evaluation on the cellular location in vitro and tumor targeting in vivo was carried out. Compared to common long-circulation liposome (PEG-Lip), more 18ß-GA- and 3-Ace-GA-modified liposomes aggregated around HepG2 cells in vitro in short time and transferred into HCC tumors in vivo for a longer time.

Conclusion: The $\beta$-configuration hydrogen atom on $\mathrm{C} 18$ position of GA played the most important role on the targeting effect. C11-carbonyl and C3-hydroxy groups of GA have certain and little influence on targeting action to HCC, respectively. In general, GA might be a promising targeting molecule for the research on liver diseases and hepatoma therapy.

Keywords: glycyrrhetinic acid, derivatives, liposomes, receptor competition, HCC-targeted effect

\section{Introduction}

Hepatocellular carcinoma (HCC) accounts for up to $90 \%$ of all malignant primary liver cancer worldwide and represents a major health threat. ${ }^{1}$ Currently, apart from surgery, patients with liver cancer are mainly treated by chemotherapy. ${ }^{2}$ However, chemotherapy is limited by a low response rate and severe systemic toxicity due to low specificity and resistance mechanisms of the chemotherapeutic agents toward cancer cells. ${ }^{3}$ Therefore, novel drug delivery systems are urgently needed to enhance the selective action of cytotoxic drugs to HCC and therefore minimize systemic toxicity to noncancerous tissues.

Glycyrrhetinic acid (GA), a pentacyclic triterpenoid, is widely present in the licorice plant and is the active aglycone of glycyrrhizin (GL). Abundant GA receptors have been confirmed on the cellular membrane of hepatocytes. ${ }^{4}$ The protein kinase $\mathrm{C}-\alpha$ was 
reported as the target binding protein of GA, which had much more expression in HCC cells than in the adjacent nontumor liver cells. ${ }^{5}$ The amount of GA receptors in tumor tissue has been found to be 1.5 - to 5 -fold more than that in normal tissue. ${ }^{6}$ Additionally, GA showed the selective toxicity toward tumor through the downregulation of glutathione. ${ }^{7}$ Recently, some GA-modified liposomes have been developed with higher drug accumulation in the liver and better anti-HCC activity. ${ }^{5-9} \mathrm{We}$ have confirmed GA receptors on HCC cells formerly according to the binding effect between fluorescence-labeled GA and GA receptors. ${ }^{10}$ Therefore, it could be expected that GA-modified liposomes could target selectively to HCC cells and tissues.

GA exists in two stereoisomers, including trans form $18 \alpha$ - and the cis form $18 \beta-\mathrm{GA}$, lying in the spatial orientation of hydrogen atom of $\mathrm{C}_{18}$. Different configurations of GA exhibit various stabilities, solubilities ${ }^{11}$ and pharmacological effects. 18 $\beta$-GA exerted protective effects against cyclophosphamide-induced hepatotoxicity. ${ }^{12} 18 \beta$-GA also showed anti-HCC proliferation effects, which could induce the HCC cells' apoptosis via modulation of inflammatory markers and inhibit HCC development by reversing hepatic stellate cell-mediated immunosuppression. ${ }^{13,14} 18 \beta-G A$ could reduce the amount of glucose release induced by glucagon in rat primary cultured hepatocytes, while $18 \alpha$-GA did not. ${ }^{15}$ Nevertheless, 11 $\beta$-hydroxysteroid dehydrogenase type 1 (11 $\beta$-HSD1) is a kind of microsomal enzyme belonging to the short-chain dehydrogenase/reductase family, which is highly expressed in many glucocorticoid target tissues, such as the liver, adipose tissue, skeletal muscle and macrophages. $18 \alpha$-GA selectively inhibited $11 \beta$-HSD1, but $18 \beta$-GA had no selectivity. ${ }^{16} 18 \alpha$-GA increased peroxisome proliferatoractivated receptor $\gamma$ expression and decreased nuclear factor- $\kappa \mathrm{B}$ DNA-binding activity, inhibiting the proliferation of activated hepatic stellate cells. ${ }^{17} 18 \alpha$-GA was reported to target prostate cancer cells by downregulation of inflammation-rated genes in DU-145 cells. ${ }^{18}$

Ishida et al have proved that a carrier-mediated transport system participated in the uptake of GL into isolated rat hepatocytes and the affinity site of the transport carrier bound to GA. ${ }^{19}$ GA is a hydrolytic product of GL with the differences of hydroxyl or glycosyl group at $\mathrm{C}_{3}$. The removal of 11-carbonyl in the ring structure of GA not only eliminated pseudoaldosterone effect but also improved its anti-inflammatory, antiulcer and antiallergic activities. ${ }^{20}$ 11-deoxy-18ß-GA (11-Deo-GA), performing a similar action of $18 \alpha-G A$, also selectively (and significantly) acted on 11- $\beta$ HSD1. ${ }^{21}$ As for anticancer properties, 11-Deo-GA induced gastric cancer cell apoptosis by upregulation of p21, downregulation of $\operatorname{cdc} 2$ and cyclin $\mathrm{B} 1$ and association with $\mathrm{BID}$ (a $\mathrm{BH} 3$ domain-only agonist) translocation from the nucleus to the mitochondria. ${ }^{22}$ These deduced that for GA's main ring structure, the hydroxyl group at $\mathrm{C}_{3}$ and the carbonyl group at $\mathrm{C}_{11}$ had certain effect on the liver or HCC cell targeting.

Thus, in this study, we focused on the targeting effect of different GA configurations and groups to HCC cells. As shown in Figure 1, 18 $\beta$-GA, 18 $\alpha$-GA, 3-acetyl-18 $\beta$-GA
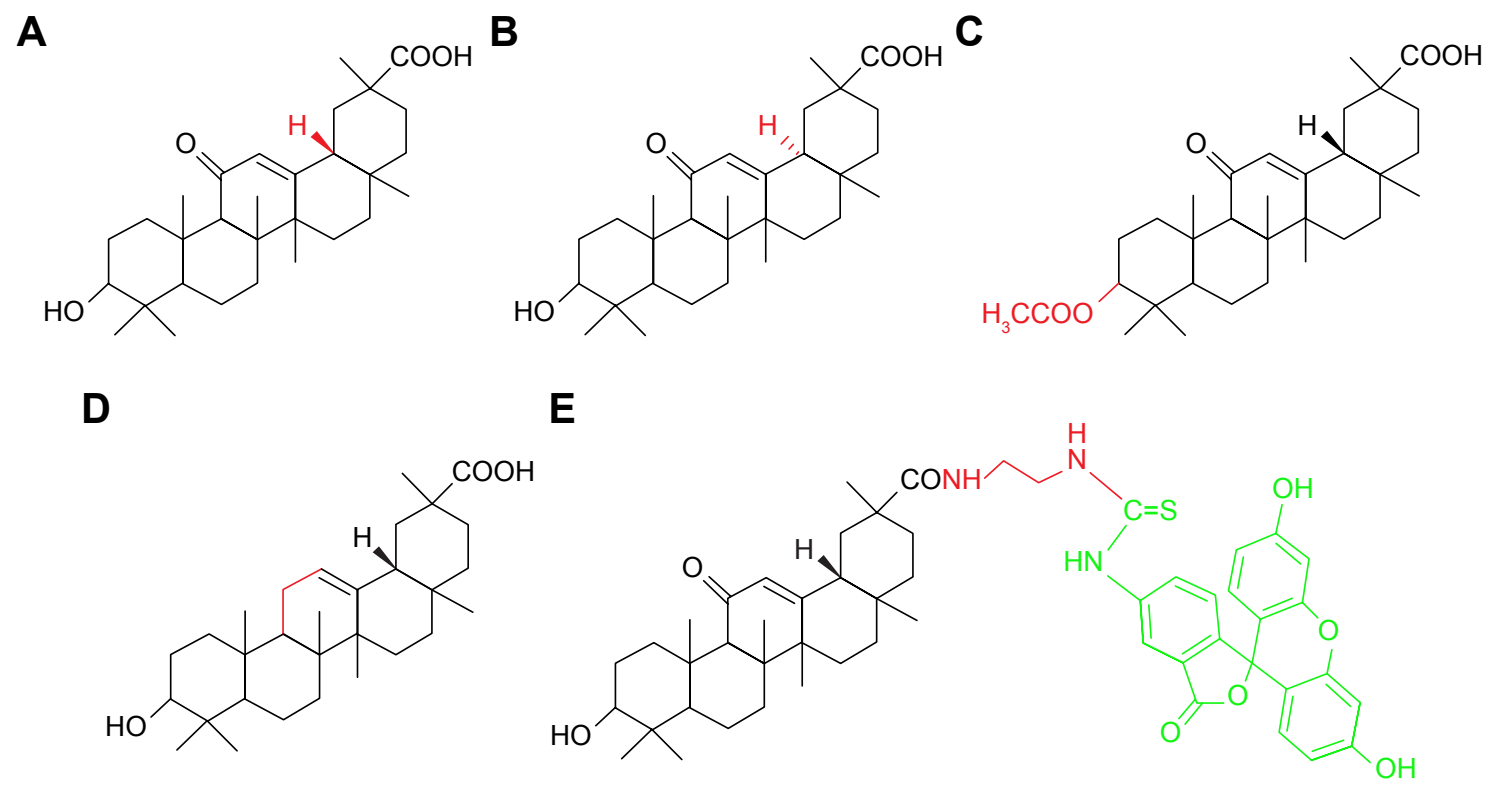

Figure I Chemical structures of I8ß-GA (A), I8 $\alpha$-GA (B), 3-Ace-GA (C), I I-Deo-GA (D) and FITC-GA (E).

Notes: The $\mathrm{C}_{3}$-hydroxyl group of GA was acetylated to get 3-Ace-GA in acetic anhydride. Clemmensen reduction reaction catalyzed by zinc amalgam was used to produce II-Deo-GA.

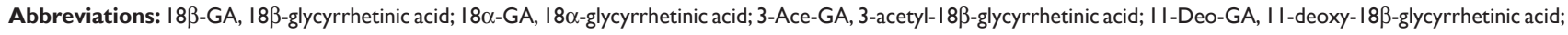
FITC-GA, fluorescein isothiocyanate-labeled I8ß-glycyrrhetinic acid. 
(3-Ace-GA) and 11-Deo-GA were obtained, and fluorescein isothiocyanate-labeled $18 \beta-G A$ (FITC-GA) was synthesized according to reported method. ${ }^{23}$ The binding site competition to HCC cells of different GA derivatives was studied. The long-circulation phospholipids with potential targeting molecular were synthesized by the GA derivatives linked with DSPE-PEG ${ }_{2000}-\mathrm{NH}_{2}$. Coumarin 6 (Cou6) and 1,1-dioctadecyl3,3,3,3-tetramethylindotricarbocyanine iodide (DiR) liposomes were prepared to evaluate the targeting effect of GA's configurations and groups in vitro and in vivo.

\section{Materials and methods Materials}


(purity 98\%) were obtained from J\&K Scientific Ltd. (Beijing, China). 3-Ace-GA, 11-Deo-GA and FITC-GA were synthesized and characterized in our laboratory. DSPEPEG $_{2000}$ (DSPE-PEG, purity $\geq 97 \%$ ) and DSPE-PEG ${ }_{2000}-\mathrm{NH}_{2}$ (DSPE-PEG-NH $\mathrm{N}_{2}$, purity $\geq 95 \%$ ) were bought from AVT Pharmaceutical Co., Ltd (Shanghai, China). Soybean phospholipid (for injection, phosphatidylcholine $\geq 85 \%$ ) and cholesterol (purity $\geq 98 \%$ ) were from Tywei Pharmaceutical Co. (Shanghai, China). DiR was from AAT Bioquest Int. (Sunnyvale, CA, USA). RIPA lysis buffer, BCA protein assay kit and Hoechst 33258 were from Beyotime Institute of Biotechnology (Shanghai, China).

Human HCC (HepG2) cells and mouse ascites hepatoma (H22) cells were obtained from Cell Bank of Chinese Academy of Sciences (Shanghai, China). HepG2 cells were cultured in Dulbecco's Modified Eagle's Medium (DMEM; Invitrogen, Carlsbad, CA, USA) with 10\% fetal bovine serum (FBS; Gibco, Waltham, MA, USA). H22 cells were cultured and passaged in Kunming mouse ascites. Male BALB/c nude mice ( $20 \pm 2 \mathrm{~g}$ ), supplied by the Department of Experimental Animals, Shenyang Pharmaceutical University (Shenyang, China), were acclimated under specific-pathogen-free conditions in the central animal facility of the university. All animal experiments were approved by the Ethics Committee of the Shenyang Pharmaceutical University and were carried out in accordance with the guidelines evaluated and approved by the ethics committee of Shenyang Pharmaceutical University.

\section{Competition of binding sites}

Approximately $2.5 \times 10^{6} \mathrm{HepG} 2$ cells were seeded into 6-well culture plates. After the cells have covered the plates, the medium was removed and the cells were washed with PBS and DMEM (without FBS) successively. The cells were treated with a series concentrations of $18 \beta-\mathrm{GA}, 18 \alpha-\mathrm{GA}$, 3-Ace-GA, 11-Deo-GA and FITC-GA in DMEM for $2 \mathrm{~h}$ at $37^{\circ} \mathrm{C}$. Then, FITC-GA was added to a final concentration of $100 \mathrm{nM}$. After co-incubation for $2 \mathrm{~h}$ at $37^{\circ} \mathrm{C}$, the cells were washed with chilled PBS and lysed with $100 \mu \mathrm{L}$ of lysis buffer in ice bath. The cell lysate was harvested, shaken and centrifuged $\left(1.2 \times 10^{4} \mathrm{rpm}\right.$ for $\left.10 \mathrm{~min}\right)$ at $4^{\circ} \mathrm{C}$. The fluorescence intensity of the supernatant was measured $\left(\lambda_{\mathrm{ex}}=490 \mathrm{~nm}\right.$, $\lambda_{\text {em }}=520 \mathrm{~nm}$ ) with the Varioskan Flash Spectral Scanning Multimode Reader (Thermo Fisher Scientific, Waltham, MA, USA). The fluorescence intensity was normalized with respect to the cells' protein content, which was determined with a BCA protein assay kit. The fluorescence intensity of different GA derivatives with FITC-GA samples and the only FITC-GA samples normalized with the content of protein in the cells was calculated as the specific binding (B) and maximum binding $\left(\mathrm{B}_{0}\right)$, respectively. The competitive curve fitting was constructed by GraphPad Prism 5.0 (GraphPad Software, La Jolla, CA, USA) software with concentration as $\mathrm{x}$-axis and specific binding ratio $\left(\mathrm{B} / \mathrm{B}_{0}\right)$ as $\mathrm{y}$-axis.

\section{Synthesis and identification of DSPE-PEGylated GA derivatives}

The GA derivatives and DSPE-PEG were linked together with amidation (Figure 2). ${ }^{24}$ In total, $235.5 \mathrm{mg} 18 \beta-\mathrm{GA}, 235.5 \mathrm{mg}$ $18 \alpha-G A, 256.2 \mathrm{mg}$ 3-Ace-GA and $228.2 \mathrm{mg}$ 11-Deo-GA $(0.5 \mathrm{mMol})$ were dissolved in anhydrous acetone with an amount of pyridine. In total, $143.8 \mathrm{mg} \mathrm{EDC} \cdot \mathrm{HCl}(0.75 \mathrm{mMol})$, $86.3 \mathrm{mg}$ NHS (0.75 mMol) and 1,100 mg DSPE-PEG were then added sequentially to the solution with stirring for $48 \mathrm{~h}$ under nitrogen protection at ambient temperature. The products were obtained by recrystallization from the condensed reaction solutions, which were mixed with an amount of icecold anhydrous ether. The precipitate was dissolved in water and dialyzed for $24 \mathrm{~h}$. The DSPE-PEGylated GA derivatives were obtained by freeze-drying at last. The ${ }^{1} \mathrm{H}-\mathrm{NMR}$ (DMSO- $d_{6}$ ) spectrum of DSPE-PEGylated GA derivatives was characterized at $300 \mathrm{~Hz}$ with an ARX-300 (600) NMR spectrometer (Bruker Optik GmbH, Ettlingen, Germany).

\section{Preparation and characterization of Cou6 liposomes}

The liposomes were prepared by a modified film dispersion method according to our previous report. ${ }^{23}$ Briefly, $18.2 \mathrm{mg}$ DSPE-PEG, $21.2 \mathrm{mg}$ 18ß-GA-PEG-DSPE, $21.2 \mathrm{mg} 18 \alpha-$ GA-PEG-DSPE, $21.4 \mathrm{mg}$ 3-Ace-GA-PEG-DSPE or $21.0 \mathrm{mg}$ 11-Deo-GA-PEG-DSPE $(6.6 \mu \mathrm{M})$ with $50 \mathrm{mg}$ phospholipid (about 1:10 molar ratio), $20 \mathrm{mg}$ cholesterol and $2 \mathrm{mg}$ Cou6 was dissolved in $10 \mathrm{~mL}$ of ethanol-dichloromethane (2:1). A thin lipid film was produced by rotary evaporation and hydrated in $10 \mathrm{~mL}$ of water at $60^{\circ} \mathrm{C}$, followed by stirring at 


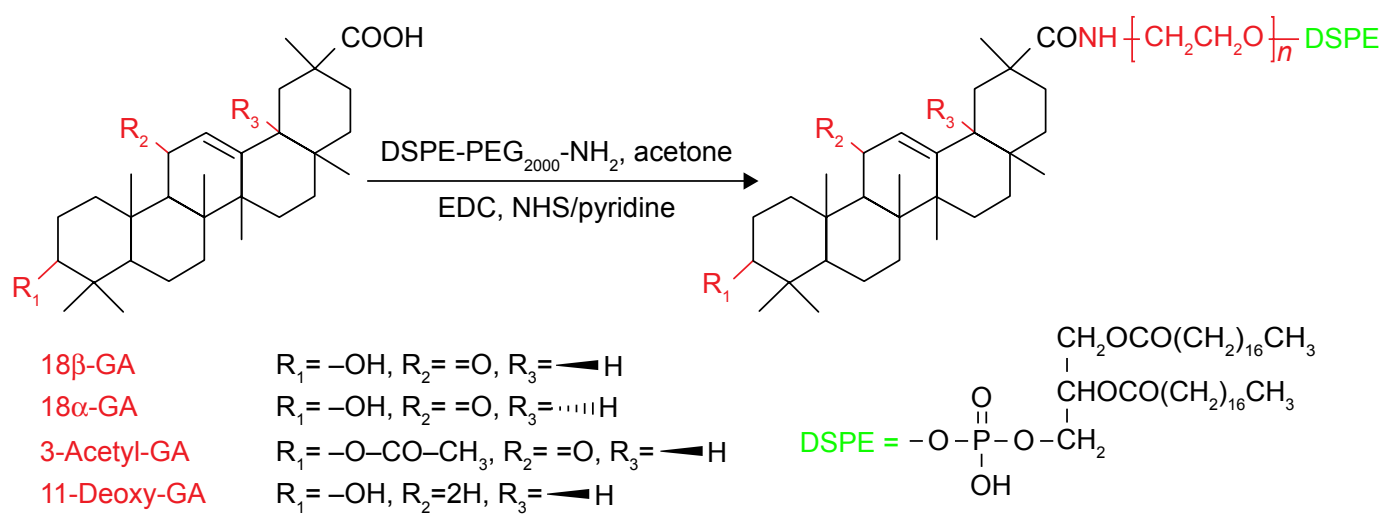

Figure 2 Synthesis of GA derivative-modified DSPE-PEG.

Notes: DSPE-PEGylated GA derivatives were synthesized by grafting the carboxyl group of GA onto the amino group of aminated DSPE. EDC, NHS and pyridine were used as catalysts.

Abbreviations: GA, glycyrrhetinic acid; DSPE, distearoyl-phosphatidylethanolamine; PEG, polyethylene glycol; EDC, I-Ethyl-3-(3-dimethylaminopropyl) carbodiimide hydrochloride; NHS, N-hydroxysuccinimide.

ambient temperature. The mixture was sonicated for $10 \mathrm{~min}$ at $200 \mathrm{~W}$. The colloidal solution obtained was then centrifuged at $1.2 \times 10^{4} \mathrm{rpm} / \mathrm{min}$ for $10 \mathrm{~min}$ and filtered through $0.22 \mu \mathrm{m}$ Millipore filters. All the procedures were conducted in darkness. The Cou6 liposomes mixed with DSPE-PEG

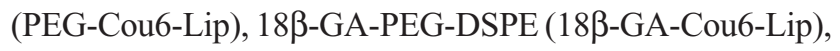
18 $\alpha$-GA-PEG-DSPE (18 $\alpha$-GA-Cou6-Lip), 3-Acel-GA-PEGDSPE (3-Ace-GA-Cou6-Lip) and 11-Deo-GA-PEG-DSPE (11-Deo-GA-Cou6-Lip) were prepared.

The particle sizes, polydispersity index (PDI) and zeta potentials of the liposomes were measured with a Nano Analyzer (ZS90; Malvern Instruments, Malvern, UK). The entrapment efficiency (EE), loading capacity (LC) and leakage (LK) of liposomes were determined with minicolumn centrifuge-fluorescence spectroscopy $\left(\lambda_{\mathrm{ex}}=497 \mathrm{~nm}\right.$, $\lambda_{\mathrm{em}}=523 \mathrm{~nm}$ ) methods.

\section{Analysis of liposomal membrane stability}

To evaluate the stability of the liposomal membranes, the resistance of the liposomes against nonionic surfactant Triton $\mathrm{X}-100$ was investigated. ${ }^{25}$ A series concentration $(0.5 \%, 1 \%$, $2 \%, 5 \%, 10 \%, 20 \%, 50 \%, 100 \%$ ) of Triton X-100 solutions was prepared. The Triton X-100 solutions $(10 \mu \mathrm{L})$ were added to the GA derivative-mediated liposomes $(190 \mu \mathrm{L})$ in the 96-well plates in triplicate. The plates were shaken for $15 \mathrm{~min}$ at $25^{\circ} \mathrm{C}$. The absorbance at $590 \mathrm{~nm}$ was measured by Multimode Reader. The turbidity was recorded as $\mathrm{A} / \mathrm{A}_{0}$ $(590 \mathrm{~nm})$, where $\mathrm{A}$ is the absorbance of samples with a predetermined concentration of Triton X-100 addition and $\mathrm{A}_{0}$ is the initial absorbance of samples.

\section{Cytotoxicity assay in vitro}

Effect of the liposomes on HepG2 cells growth was assessed by MTT assay. In total, $5 \times 10^{3} \mathrm{HepG} 2$ cells were seeded into the 96-well culture plates in quintuplicate and incubated overnight. The medium was then replaced with the GA derivative-mediated liposomes at gradient Cou6 concentrations of $2 \mu \mathrm{g} / \mathrm{mL}$ (low), $10 \mu \mathrm{g} / \mathrm{mL}$ (medium) and $50 \mu \mathrm{g} / \mathrm{mL}$ (high). After incubation for $6 \mathrm{~h}$, the cultured medium was then discarded and refreshed with DMEM. In total, $20 \mu \mathrm{L}$ of MTT solution ( $5 \mathrm{mg} / \mathrm{mL}$ in PBS) was added to each well for additional $4 \mathrm{~h}$ of incubation. Formazan was dissolved in $150 \mu \mathrm{L}$ of DMSO, and the absorbance at $570 \mathrm{~nm}$ was measured using the Multimode Reader. The inhibition was calculated according to the absorbance.

\section{Confocal observation}

Laser scanning confocal microscopy was used to visualize the subcellular localization of different Cou6 liposomes. ${ }^{26}$ HepG2 cells were cultured on sterile microscope slides in the 6 -well culture plates $\left(2 \times 10^{5}\right.$ cells/well $)$ and incubated overnight. The media were replaced by the five liposomes in DMEM (without FBS), and the cells were further incubated for $0.25,1$ and $6 \mathrm{~h}$. Then, the media were removed and the cells were washed 3 times with cold PBS. Hoechst 33258 $(10 \mu \mathrm{g} / \mathrm{mL}, 10 \mathrm{~min})$ was used to localize nuclei. Finally, the cells were fixed with $4 \%$ formaldehyde at ambient temperature and captured by laser scanning confocal microscope (Olympus FV1000-IX81; Olympus Corporation, Tokyo, Japan). The content of Cou6 in each sample was measured accordingly as we reported previously. ${ }^{10}$

\section{In vivo targeting ability study}

The DiR liposomes containing DSPE-PEG (PEG-DiR-Lip) and mediated by different GA derivatives (18 $\beta-G A-D i R-$

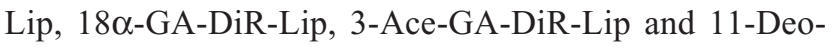
GA-DiR-Lip) were prepared according to the previously 
mentioned method. Male BALB/c mice were inoculated subcutaneously in the right axillary fossa with $0.2 \mathrm{~mL}$ of $\mathrm{H} 22$ cell suspension $\left(2 \times 10^{6}\right.$ cells $\left./ \mathrm{mL}\right)$. Once the tumor reached a volume of $150-200 \mathrm{~mm}^{3}$, the $\mathrm{H} 22$ tumor-bearing mice were obtained. The mice were divided into five groups and intravenously injected with $0.2 \mathrm{~mL}$ of various DiR liposomes. In the period of $12 \mathrm{~h}$ postinjection, the mice under anesthetic state were scanned using a Kodak In Vivo Imaging System FX Pro (Carestream Health Inc., Rochester, NY, USA) at different time.

\section{Statistical analysis}

All the experiments were performed in triplicate, and the values are presented as mean \pm standard deviation. The data were analyzed by applying one-way ANOVA, followed by the methods of Student's $t$-test. $p$-value $<0.05$ indicated statistically significant differences.

\section{Results and discussion Competitive effect on binding sites}

According to the differences in the configurations and in the main modified parts at $\mathrm{C}_{3}$-hydroxyl and $\mathrm{C}_{11}$-carbonyl groups of $\mathrm{GA},{ }^{27}$ the compounds including $18 \beta-\mathrm{GA}, 18 \alpha-\mathrm{GA}$, 3-Ace-GA and 11-Deo-GA were obtained. As is known, receptor competition is increasingly common to discovery of new drugs ${ }^{28}$ and screen for targeting ligands. Higher binding effect means stronger physiological activity and longer signaling pathway influence. The results on the competitive effect of GA derivatives with FITC-GA in HepG2 cells are shown in Figure 3. The reversible binding of receptors and

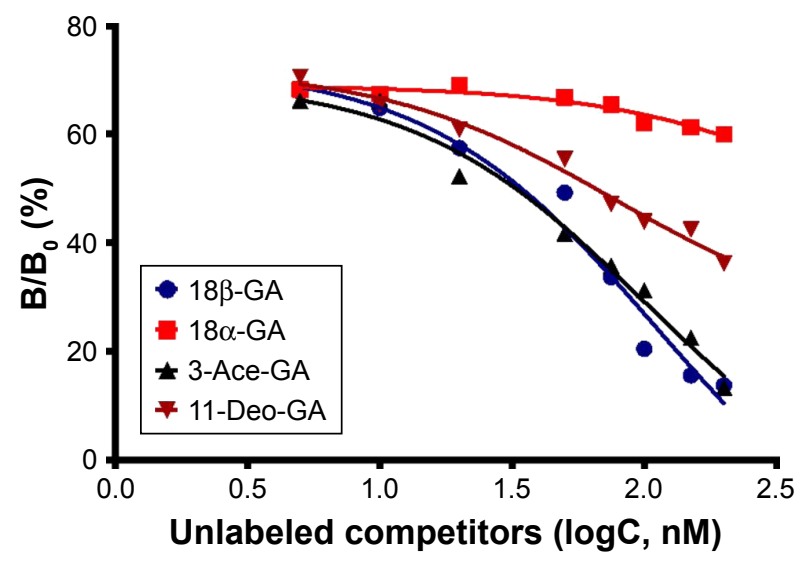

Figure 3 GA derivative competitive curve with FITC-GA binding to GA receptors in HepG2 cells.

Notes: The curves were fitted with GraphPad Prism 5.0 software. $B / B_{0}$ is expressed as the percentage of maximum specific binding sites. Data are representative of three independent experiments and the SD was not listed.

Abbreviations: GA, glycyrrhetinic acid; FITC-GA, fluorescein isothiocyanatelabeled I8 $\beta$-glycyrrhetinic acid; $B$, specific binding; $B_{0}$, maximum binding; I8 $\beta$-GA, I8 $\beta$-glycyrrhetinic acid; $18 \alpha-G A, 18 \alpha$-glycyrrhetinic acid; 3-Ace-GA, 3-acetyl-18 $\beta$ glycyrrhetinic acid; II-Deo-GA, II-deoxy-18ß-glycyrrhetinic acid. ligands accounted for $70 \%$ of maximum binding $\left(\mathrm{B}_{0}\right)$ of FITC-GA after the inhibitor (18 $\beta-G A, 18 \alpha-G A, 3-A c e-G A$ or 11-Deo-GA) was added. $\mathrm{EC}_{50}$ values of different $\mathrm{GA}$ derivative competition to binding sites in HepG2 cells were calculated. Among them, 18 $\beta$-GA decreased the specific binding ratio $\left(\mathrm{B} / \mathrm{B}_{0}\right)$ significantly. The $\mathrm{EC}_{50}$ of $18 \beta-\mathrm{GA}$ was $100.1 \mathrm{nM}$. B/B $\mathrm{B}_{0}$ value decreased to $10 \%$ of $\mathrm{B} / \mathrm{B}_{0}$ when $200 \mathrm{nM}$ of $18 \beta-G A$ was added. The competitive curve of $18 \alpha-\mathrm{GA}$ with FITC-GA was flatter and the $\mathrm{EC}_{50}$ was $563.1 \mathrm{nM}$ indicating the weak binding effect of GA receptors and competitive ability with FITC-GA. It demonstrated that the $18-\mathrm{H}$ configuration of GA influenced the binding effect greatly. The addition of 3-Ace-GA gave a similar competitive curve of $18 \beta-\mathrm{GA}$ and $111.7 \mathrm{nM}$ of $\mathrm{EC}_{50}$, indicating a little influence of 3-OH of GA. The competitive curve of 11-Deo-GA lay between $18 \alpha-\mathrm{GA}$ and 3-Ace-GA, with $121.2 \mathrm{nM}$ of $\mathrm{EC}_{50}$ demonstrating the competitive effect with FITC-GA. 11-Carbonyl group influenced the targeting action of GA.

\section{Characterization of GA derivative- PEG-DSPE}

The DSPE-PEGylated GA derivatives were synthesized by grafting the carboxyl group of GA onto the amino group of aminated DSPE. The ${ }^{1} \mathrm{H}-\mathrm{NMR}$ spectrum in Figure 4 shows that the signals at $\delta 0.68-1.11 \mathrm{ppm}$ belonged to the methylene and the methyl groups of the pentacyclic triterpenoid structure of GA. The peaks at $\delta 1.30-1.40 \mathrm{ppm}$ were $19-\mathrm{H}$ and at $\delta 5.30-5.50 \mathrm{ppm}$ were $12-\mathrm{H}$ of the GA rings. The peaks at $\delta 1.20-1.35 \mathrm{ppm}$ and $\delta 3.30-3.60 \mathrm{ppm}$ mainly attributed to the $-\mathrm{CH}_{2}$ protons of stearic acid groups of DSPE and the glycol blocks of $\mathrm{PEG}_{2000}$, respectively. In the ${ }^{1} \mathrm{H}-\mathrm{NMR}$ spectrum, a single peak with one unit area at $\delta 7.40-7.80$ ppm was found (18ß-GA-PEG-DSPE $7.78 \mathrm{ppm}, 18 \alpha$-GA 7.63 ppm, 3-Ace-GA 7.50 ppm, 11-Deo-GA 7.47 ppm), which belonged to the $-\mathrm{CO}-\mathrm{NH}-$ proton when $-\mathrm{COOH}$ of GA derivatives acetylated with the $-\mathrm{NH}_{2}$ of DSPE-PEG-NH ${ }_{2}$. The integration value ratio for the peak of amide group and the peak of methyl $(\delta 0.75-0.83)$ in stearyl group was about 1:6. Therefore, the long-circulation phospholipids with GA derivatives have been successfully synthesized. The yield of 18$\beta$-GA-PEG-DSPE, 18 $\alpha$-GA-PEG-DSPE, 3-Ace-GAPEG-DSPE and 11-Deo-GA-PEG-DSPE was $69.3 \%, 53.2 \%$, $75.0 \%$ and $66.4 \%$, respectively.

\section{Pharmaceutical characters of liposomes}

Liposome size is an important factor that can influence drug dosage, uptake, targeting, clearance and lysosomal accumulation. ${ }^{29}$ The liposomal characters are shown in Table 1. The particle sizes of the five liposomes were less 
A

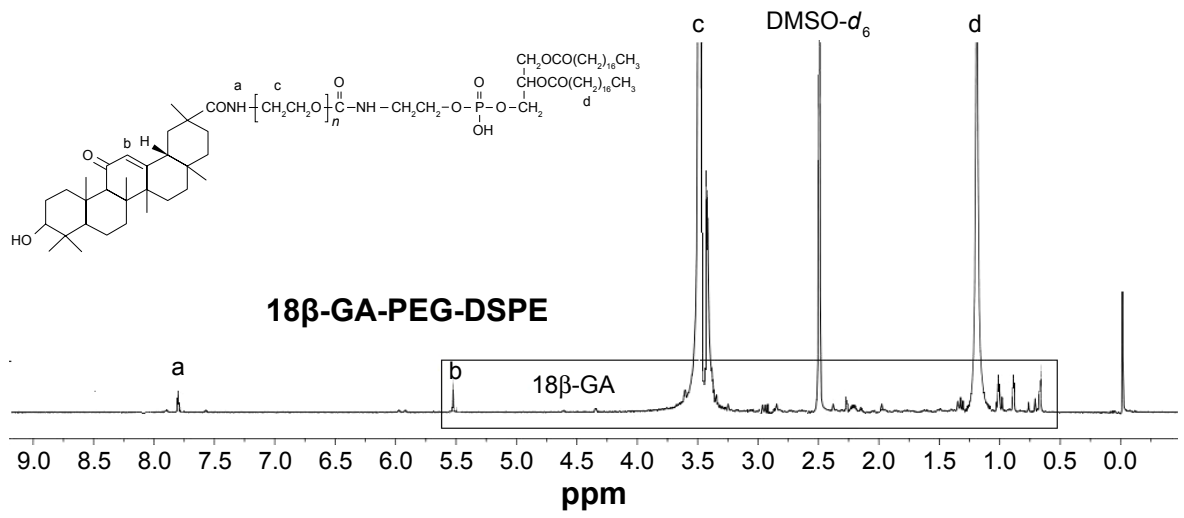

B

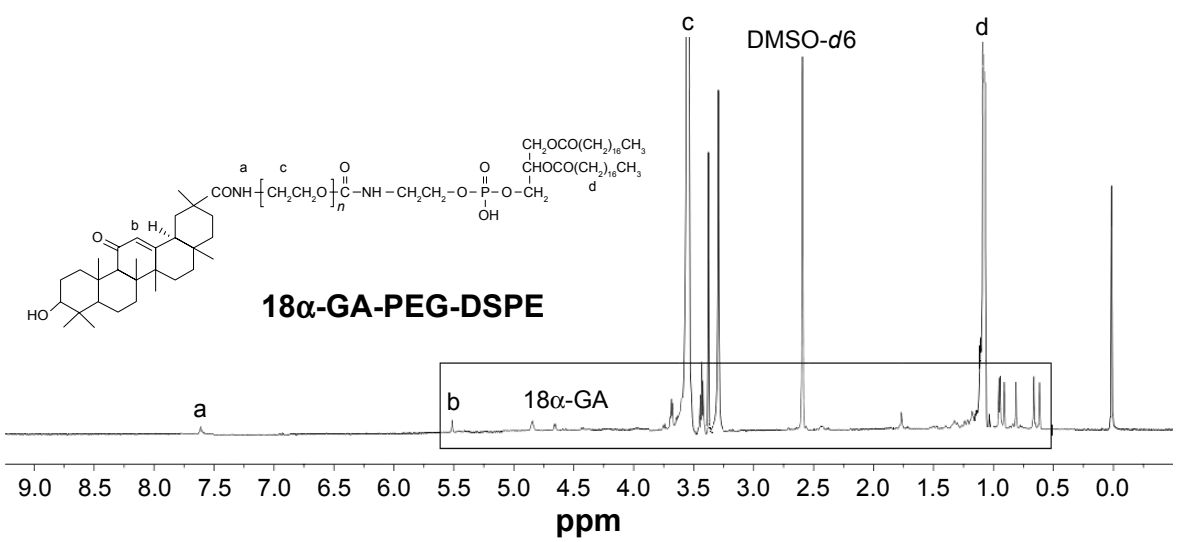

C

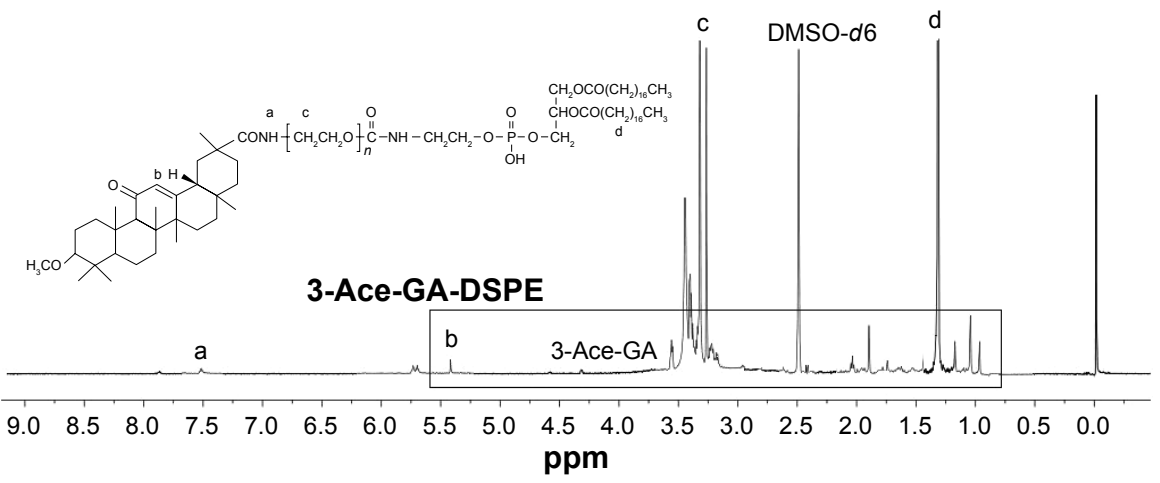

D

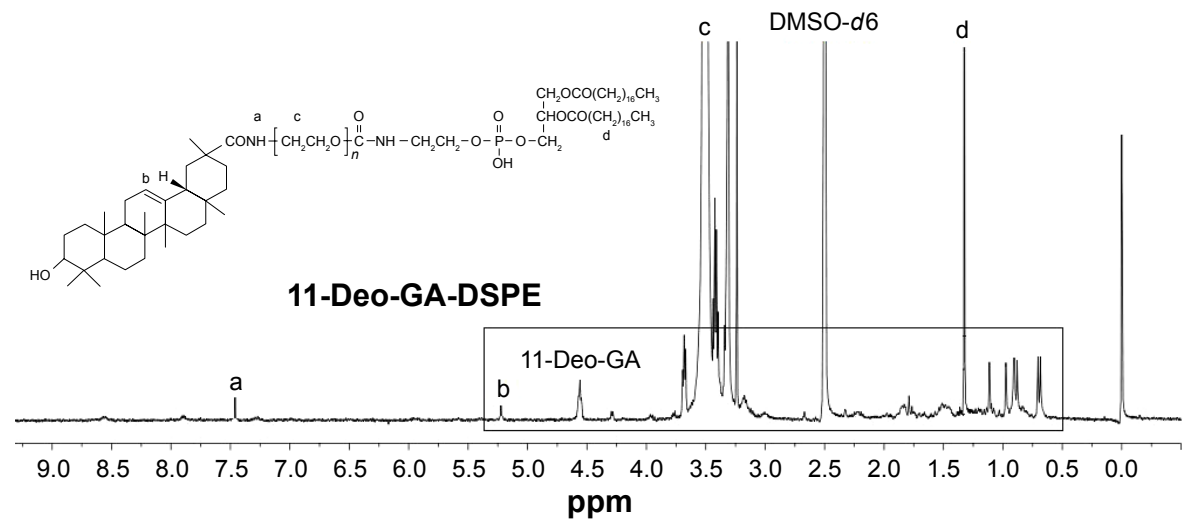

Figure 4 'H-NMR characterization of DSPE-PEGylated GA derivatives: (A) PEGylated I8ß-GA, (B) DSPE-PEGylated I8 $\alpha$-GA, (C) PEGylated 3-Ace-GA, (D) DSPE-PEGylated II-Deo-GA.

Note: The samples of DSPE-PEGylated GA derivatives were dissolved in DMSO- $d_{6}$ and characterized with an NMR spectrometer.

Abbreviations: 'H-NMR, proton nuclear magnetic resonance; DSPE, distearoyl-phosphatidylethanolamine; PEG, polyethylene glycol; GA, glycyrrhetinic acid. 
Table I Characteristics of GA derivative-mediated liposomes

\begin{tabular}{|c|c|c|c|c|c|c|c|}
\hline Liposomes & $\begin{array}{l}\text { Particle } \\
\text { size }(\mathrm{nm})\end{array}$ & PDI & $\begin{array}{l}\text { Zeta potential } \\
(\mathrm{mV})\end{array}$ & EE (\%) & LC (mg/g) & LK (\%) & $\begin{array}{l}\mathrm{DC}_{50} \\
(\% \circ)\end{array}$ \\
\hline PEG-Cou6-Lip & $177.3 \pm 26.6$ & $0.182 \pm 0.012$ & $-10.03 \pm 0.93$ & $70.33 \pm 2.70$ & $18.75 \pm 0.72$ & $6.87 \pm 2.07$ & 0.566 \\
\hline I8ß-GA-Cou6-Lip & $162.2 \pm 20.0$ & $0.196 \pm 0.017$ & $-18.82 \pm 0.65$ & $75.14 \pm 2.15$ & $20.04 \pm 0.57$ & $5.76 \pm 1.27$ & 0.380 \\
\hline I8 $\alpha$-GA-Cou6-Lip & $169.9 \pm 14.1$ & $0.207 \pm 0.022$ & $-|8.4| \pm 0.43$ & $76.50 \pm 1.02$ & $20.40 \pm 0.27$ & $6.05 \pm 0.84$ & 0.354 \\
\hline 3-Ace-GA-Cou6-Lip & $158.0 \pm 28.3$ & $0.209 \pm 0.008$ & $-18.20 \pm 1.07$ & $82.40 \pm 0.80$ & $21.97 \pm 0.21$ & $5.96 \pm 1.10$ & 0.207 \\
\hline I I-Deo-GA-Cou6-Lip & $152.4 \pm 10.2$ & $0.213 \pm 0.026$ & $-18.48 \pm 0.78$ & $66.18 \pm 1.17$ & $|7.65 \pm 0.3|$ & $6.37 \pm 0.45$ & 0.253 \\
\hline
\end{tabular}

Note: Data expressed as mean \pm standard deviation $(n=3)$.

Abbreviations: GA, glycyrrhetinic acid; PDI, polydispersity index; EE, encapsulation efficiency; LC, loading capacity; LK, leakage; $D C_{50}$, Triton X-100 concentration destroyed

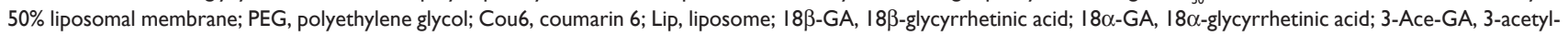
18ß-glycyrrhetinic acid; II-Deo-GA, II-deoxy-I8ß-glycyrrhetinic acid.

than $180 \mathrm{~nm}$, which were analyzed by dynamic light scattering. The sizes of Cou6 liposomes with DSPE-PEGylated GA derivatives were smaller than those of PEG-Cou6Lip. The possible reason might be that the hydrophobicity of GA derivatives wrapped the PEG chain tightly and squeezed the particles further. The PDI (0.182-0.213) demonstrated relatively narrow distribution of the liposomes. The zeta potential of the five liposomes was negative ranging from -10 to $-18 \mathrm{mV}$. With the addition ofDSPE-PEGylated GA derivatives, the zeta potential was $8 \mathrm{mV}$ or so lower. A greater zeta potential is necessary to inhibit liposomal aggregation. ${ }^{30}$ The LK of the Cou6 liposomes was lower $(<7 \%, 14 \mathrm{~d})$. The GA derivative-mediated liposomes showed higher stability with lower potential and lower LK. As a regulatory requirement, $\mathrm{EE}$ is a greatly significant parameter to control the quality of the liposomes. ${ }^{31}$ Results showed that the values of $\mathrm{EE}$ and the LC of the five liposomes were all higher than $65 \%$ and $17.5 \mathrm{mg} / \mathrm{g}$. 3-Ace-GA-Cou6-Lip and 11-DeoGA-Cou6-Lip showed the highest and lowest values of EE, respectively. The DSPE-PEGylated GA derivatives had no significant effect on the EE and LC of Cou6. Therefore, the liposomes exhibited good preparation characteristics. Because the optimum size of PEG-liposomes for prolonged circulation is $160-220 \mathrm{~nm},{ }^{32}$ we could expect a good long-circulation effect of these GA derivative-modified liposomes.

\section{Liposomal membrane stability}

Triton X-100, a polyoxyethylene nonionic surfactant, has been used to determine the membrane stability of different Cou6 liposomes. Three relevant transitions would take place when Triton X-100 was added into the liposomal suspension. First, lower concentration led to a slight increase in the size of liposome, which might be attributed to the incorporation of surfactant monomers in the lipid bilayer. Second, increasing surfactant amounts led to a progressive decrease in intensity for mixed liposomes, which corresponded to the saturation of Triton X-100 in bilayer and the formation of lipid micelles. The size of micelles was far less than that of liposomal particles. Finally, higher concentration made a slight fall in the particle size, which might be attributed to the progressive enrichment in Triton X-100 of the mixed micelles formed. ${ }^{33}$

The variations of relative turbidity (RTU) for the suspension vs Triton X-100 concentration were plotted in logarithmic coordinates (Figure 5). The spots showed the inverted $S$-type distribution when a series concentration of Triton $\mathrm{X}-100$ was added into the liposomal suspensions. The RTU expressed horizontal distribution when lower $(<0.15 \%)$ and higher $(>0.60 \%$ ) concentrations of Triton X-100 were added because of the less membrane action and thorough membrane destroy, respectively. When a medium concentration of Triton $\mathrm{X}-100$ was added, the liposomal membrane was destroyed in a concentration-dependent manner and the RTU decreased sharply; a straight line (linear regression) was fitted for the relationship of RTU to logarithm concentration of Triton X-100. When half of the liposomal membrane was destroyed (RTU $=0.5$ ), the destruction concentration of Triton X-100 $\left(\mathrm{DC}_{50}\right.$ ) was calculated (Table 1) to evaluate the stability of the membrane. The results showed that the membrane of PEGCou6-Lip was extremely stable and the membrane stability of GA derivative-modified liposomes decreased slightly.

\section{Cytotoxicity assay}

The cytotoxic effects of PEG-Cou6-Lip, 18ß-GA-Cou6-Lip, 18 $\alpha$-GA-Cou6-Lip, 3-Ace-GA-Cou6-Lip and 11-Deo-GACou6-Lip on HepG2 cells in $6 \mathrm{~h}$ were investigated by MTT assay. As shown in Figure 6, different concentrations $(2,10$, $50 \mu \mathrm{g} / \mathrm{mL}$ ) of Cou6 used in different liposomes showed certain cytotoxicity against HCC cells. No apparent cytotoxicity was observed at low concentration (IR $<2.0 \%$ ). Compared to PEG-Cou6-Lip, there were no significant differences in cytotoxicity at $10 \mu \mathrm{g} / \mathrm{mL}$ of Cou6 in four GA 

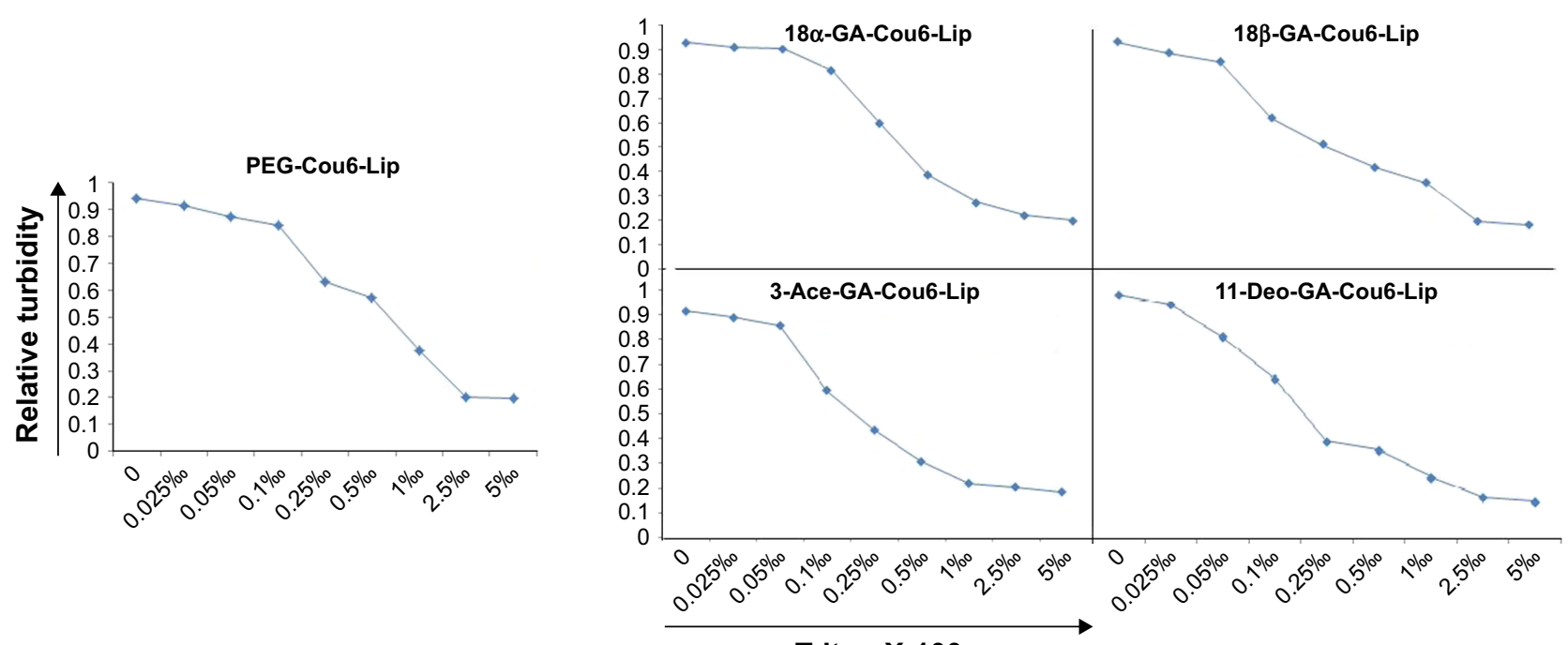

Triton X-100

Figure 5 Membrane stability of different Cou6 liposomes treated with Triton X-100.

Notes: Nonionic surfactant Triton X-100 was used to evaluate liposomal membrane stability. The variations of relative turbidity for the suspension as $y$-axis vs Triton X-I00 concentration as $\mathrm{x}$-axis were plotted in logarithmic coordinates. The spots demonstrated the inverted S-type distribution.

Abbreviations: Cou6, coumarin 6; PEG, polyethylene glycol; Lip, liposome; I8 $\alpha$-GA, I8 $\alpha$-glycyrrhetinic acid; I8 $\beta$-GA, I8 3 -glycyrrhetinic acid; 3-Ace-GA, 3-acetyl-I8 $\beta$ glycyrrhetinic acid; II-Deo-GA, II-deoxy-I8ß-glycyrrhetinic acid.

derivative-mediated liposomes. High concentration action showed significant differences in cell viability. As a result, $10 \mu \mathrm{g} / \mathrm{mL}$ of Cou6 in liposomes was chosen as the optimal concentration in the further trial and $6 \mathrm{~h}$ was taken as the longest action time.

\section{Cellular localization}

Cou6 with high quantum yield has been widely used in cellular localization of nano-drug delivery system. Most cells

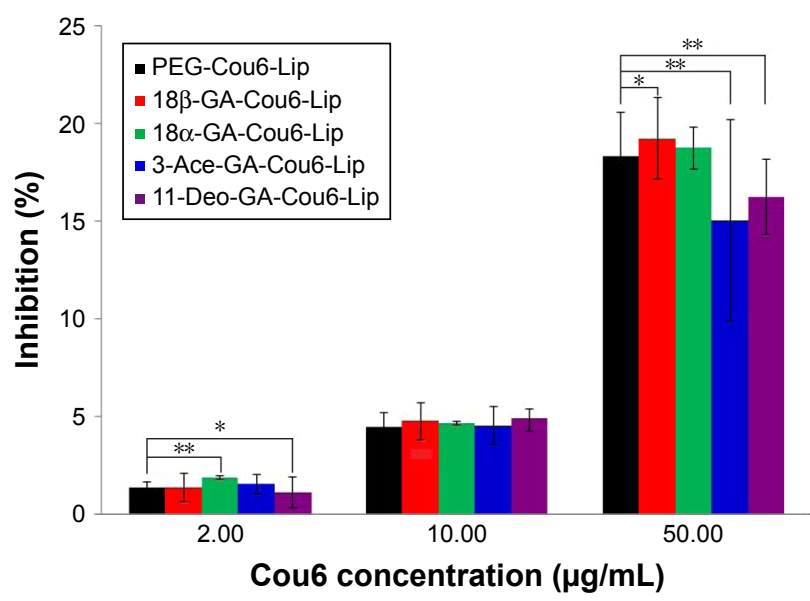

Figure 6 Inhibition of different Cou6 liposomes in HepG2 cells.

Notes: HepG2 cells were treated with low (2 $\mathrm{gg} / \mathrm{mL}$ in Cou6), medium ( $10 \mu \mathrm{g} / \mathrm{mL}$ in Cou6) and high ( $50 \mu \mathrm{g} / \mathrm{mL}$ in Cou6) concentrations of PEG-Cou6-Lip, 18ß-GA-Cou6-Lip, I8 $\alpha$-GA-Cou6-Lip, 3-Ace-GA-Cou6-Lip and I I-Deo-GA-Cou6-Lip. In total, $10 \mu \mathrm{g} / \mathrm{mL}$ of Cou6 in liposomes was chosen as the optimal concentration in the further trial in vitro and in vivo. Data expressed as mean \pm standard deviation $(n=3)$. $* P<0.05$, $* * P<0.01$. Abbreviations: Cou6, coumarin 6; PEG, polyethylene glycol; Lip, liposome;

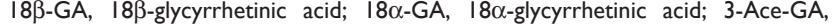

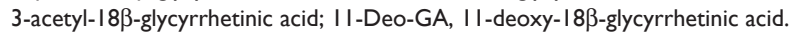

have no background influence in the fluorescence spectrum range of Cou6. In addition, raw Cou6 cannot be directly internalized by the cells. ${ }^{34}$ In other words, the fluorescence measured in the uptake samples reflects the liposomes taken up by the cells but not the released Cou6. Figure 7 shows the confocal laser scanning microscopy (CLSM) images and quantitative analysis of different liposomes loading Cou6 after 15 min, $2 \mathrm{~h}$ and $6 \mathrm{~h}$ in HepG2 cells. For 18 $\beta$-GA-Cou6-Lip and 3-Ace-GA-Cou6-Lip, much more green fluorescence intensity was aggregated around the HepG2 cells after incubation for $15 \mathrm{~min}$, demonstrating a good affinity to the cytomembrane. Meanwhile, weak fluorescence was observed near and in the cells when the other three liposomes were added. After co-incubation for $2 \mathrm{~h}$, the green fluorescence was internalized and gathered in the cells. The HCC cells treated with 18ß-GA-Cou6-Lip and 3-Ace-GA-Cou6-Lip showed distinct cell outlines with strong fluorescence intensity. However, the cells treated with PEG-Cou6-Lip, 18 $\alpha$-GA-Cou6-Lip and 11-Deo-GACou6-Lip showed obscure outlines. The green fluorescence intensity was enhanced with increasing the incubation time for all the liposomes. Furthermore, after co-incubation for $6 \mathrm{~h}$, most fluorescence was gathered in the cells and all the liposomes were internalized by cells. It was difficult to distinguish the binding sites of the cells. The results indicated that GA-modified nano-carriers showed liver and HCC targeting effects. The $\mathrm{C}_{3}$-hydroxyl group of GA had little influence on the targeting ability, which was consistent with the reports 

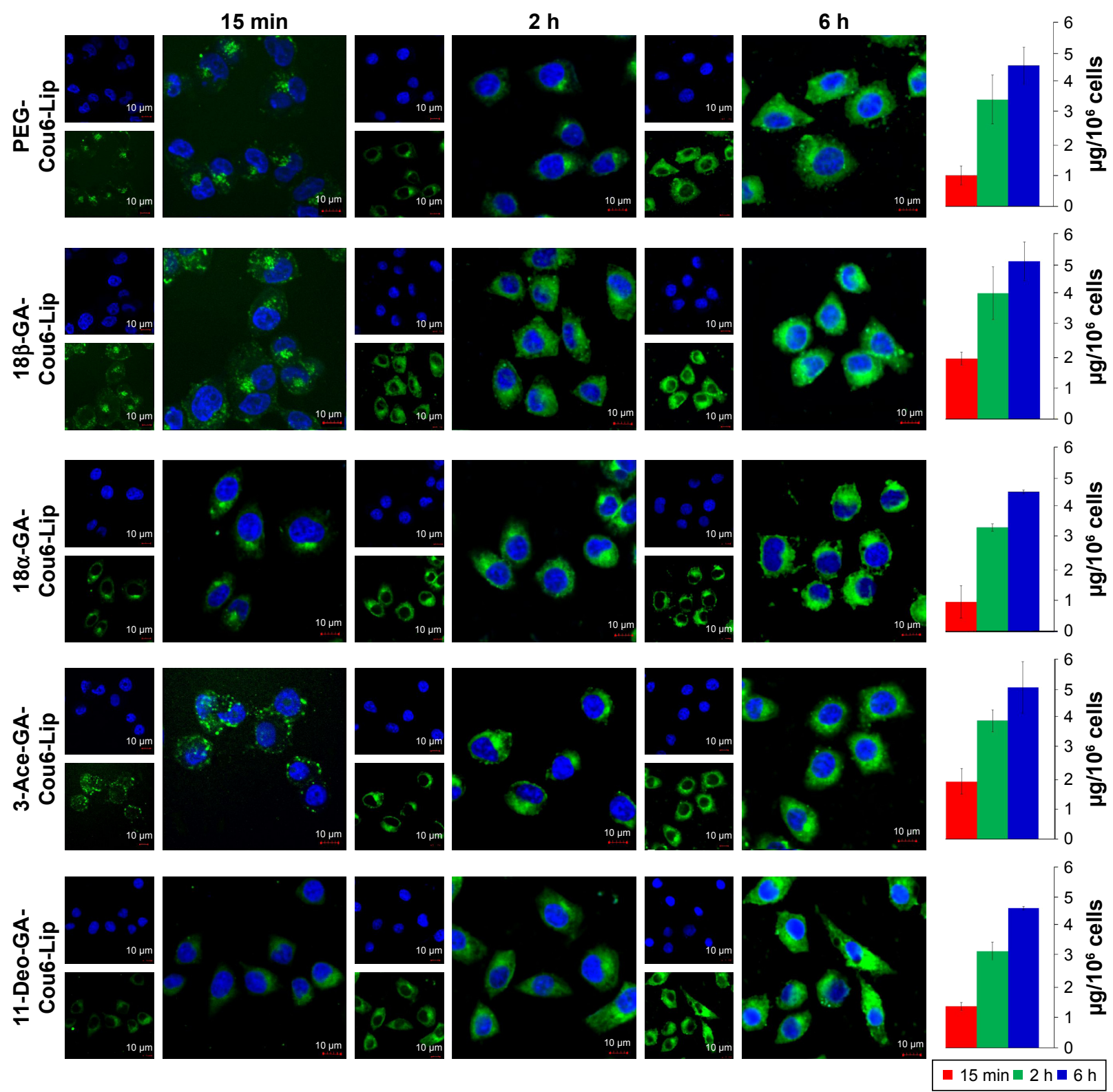

Figure 7 CLSM images of the cellular localization of Cou6 liposomes and Cou6 contents in different HepG2 cell samples.

Notes: The HepG2 cells were incubated with PEG-Cou6-Lip, I8ß-GA-Cou6-Lip, I8 $\alpha$-GA-Cou6-Lip, 3-Ace-GA-Cou6-Lip or I I-Deo-GA-Cou6-Lip for different times. Cou6 liposomes were green in color. The nuclei were blue stained using Hoechst 33258. Scale bars represent $10 \mu \mathrm{m}$.

Abbreviations: CLSM, confocal laser scanning microscopy; Cou6, coumarin 6; PEG, polyethylene glycol; Lip, liposome; I8 $\beta$-GA, I8 $\beta$-glycyrrhetinic acid; I8 $\alpha$-GA,

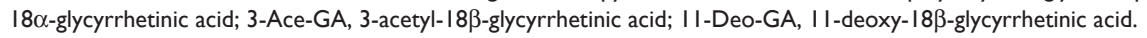

of Tian et al. ${ }^{35}$ The spatial configuration and $\mathrm{C}_{11}$-carbonyl group affected the HCC cell targeting of GA.

\section{Tumor targeting in vivo}

The in vivo biodistribution and targeting ability of the liposomes in mice were evaluated using a near-infrared fluorescence image system. DiR was chosen as a fluorescent marker, which is a type of near-infrared fluorescent dye with an excitation spectrum of $750 \mathrm{~nm}$ and an emission spectrum of $782 \mathrm{~nm}$. As a lipophilic tracer, DiR allowed the noninvasive tracking of cells for several days in vivo. ${ }^{36}$ Figure 8 shows the real-time images in $\mathrm{H} 22$ tumor-bearing nude mice at $0.5,2$ and $12 \mathrm{~h}$ after intravenous (caudal-vein) injection of PEG-DiR-Lip, 18ß-GA-DiR-Lip, 18 $\alpha$-GA-DiRLip, 3-Ace-GA-DiR-Lip and 11-Deo-GA-DiR-Lip. All the liposomes had a time-dependent liver and tumor accumulation in the mice. Most DiR accumulated in the liver at $0.5 \mathrm{~h}$ postadministration of the liposomes, and then there was a decrease in the fluorescence intensity from 2 to $12 \mathrm{~h}$. With the prolongation of time, the fluorescence intensity in the tumor 


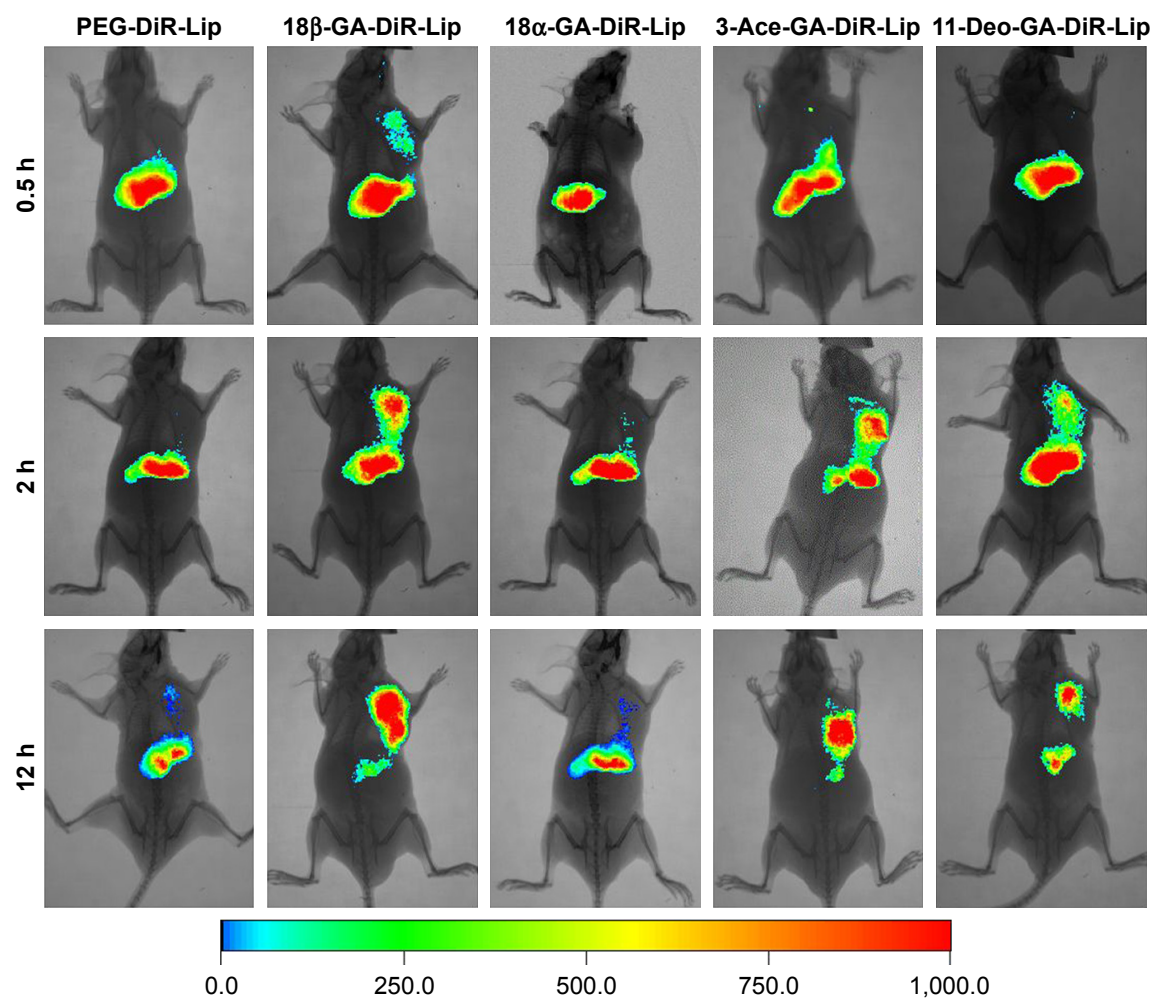

Figure 8 In vivo noninvasive images of time-dependent whole-body imaging of $\mathrm{H} 22$ tumor-bearing nude mice after injection of different liposomes.

Notes: The mice were administrated intravenously PEG-DiR-Lip, I8 $\beta$-GA-DiR-Lip, I8 $\alpha$-GA-DiR-Lip, 3-Ace-GA-DiR-Lip and I I-Deo-GA-DiR-Lip through tail vein for 0.5, 2 and 12 h. The fluorescent images were captured using an In Vivo Imaging System.

Abbreviations: PEG, polyethylene glycol; DiR, I,I-dioctadecyl-3,3,3,3-tetramethylindotricarbocyanine iodide; Lip, liposome; I8 $\beta$-GA, I8 $\beta$-glycyrrhetinic acid; I8 $\alpha$-GA,

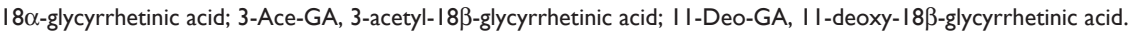

region was increased. $18 \beta-G A-$ and 3-Ace-GA-modified liposomes revealed distinct uptake, which were transported more quickly to the HCC tumors after $2 \mathrm{~h}$ of injection. The highest accumulation in an $\mathrm{H} 22$ xenograft tumor model after $12 \mathrm{~h}$ of administration was found, which was consistent with CLSM results of the two liposomes in HCC cells. As to PEG-DiR-Lip and 18 $\alpha$-GA-DiR-Lip, only a little fluorescence was measured in the tumor tissues. However, the fluorescence intensity in the liver decreased significantly. The targeting effect of 11-Deo-GA-DiR-Lip differed from 18ß-GA-DiRLip and 3-Ace-GA-DiR-Lip, as well as PEG-DiR-Lip and $18 \alpha-G A-D i R-L i p$. Part of liposome was transported and accumulated in the HCC tumors. There was no obvious fluorescent signal appearing in kidney tissue. This suggested that the metabolism in the liver was the main elimination route of GA derivative-modified liposomes. The tumor-targeting results indicated that the liposomes were transferred quickly in the liver. There were no significant differences whether GA derivatives modified or not. Different GA derivative ligands showed different HCC tumor-targeting effects. The configuration and groups of GA influenced different degrees on the targeting effects.

\section{Conclusion}

GA receptor has been deemed to be a promising receptor to target HCC attributing to its safety and pharmacological potential. Focusing on the differences of structure configurations and active groups, four GA derivatives (18 $\beta-\mathrm{GA}$, 18 $\alpha$-GA, 3-Ace-GA and 11-Deo-GA) and mediated liposomes (18 $\beta$-GA-Lip, 18 $\alpha$-GA-Lip, 3-Ace-GA-Lip and 11-Deo-GA-Lip) were developed to show different abilities to target the HCC cells and HCC tumors. $18 \beta$-GA and 3-Ace-GA showed significantly competitive effects with FITC-GA on HepG2 cells. The effect decreased in turn for 11-Deo-GA and $18 \alpha-G A-L i p$. The liposomes modified with GA derivatives showed higher loading ability and better stability. Compared to common long-circulation liposome (PEG-Lip), more 18$\beta$-GA- and 3-Ace-GA-modified liposomes were aggregated around HepG2 cells in vitro in short time and were transferred into HCC tumors in vivo for a longer time. There were no significant differences between 18 $\alpha$-GA-Lip and PEG-Lip on HCC targeting. In addition, 11-Deo-GA-Lip showed certain targeting effect. Therefore, it can be concluded that GA shows the targeting action to $\mathrm{HCC}$ cells and $\mathrm{HCC}$ tumors. The $\beta$-configuration hydrogen atom at $\mathrm{C}_{18}$ position 
of GA contributes the most targeting effect. $\mathrm{C}_{11}$-carbonyl and $\mathrm{C}_{3}$-hydroxy groups of GA have certain and little influences on the targeting action to $\mathrm{HCC}$, respectively.

\section{Acknowledgment}

This work was supported by the grants from the Science and Technology Department of Liaoning Province (2013022064, 201602312).

\section{Disclosure}

The authors report no conflicts of interest in this work.

\section{References}

1. Llovet JM, Villanueva A, Lachenmayer A, Finn RS. Advances in targeted therapies for hepatocellular carcinoma in the genomic era Nat Rev Clin Oncol. 2015;12(7):408-424.

2. Li L, Wang H. Heterogeneity of liver cancer and personalized therapy. Cancer Lett. 2016;379(2):191-197.

3. Zhu X, Tsend-Ayush A, Yuan Z, et al. Glycyrrhetinic acid-modified TPGS polymeric micelles for hepatocellular carcinoma-targeted therapy. Int J Pharm. 2017;529(1-2):451-464.

4. Negishi M, Irie A, Nagata N, Ichikawa A. Specific binding of glycyrrhetinic acid to the rat liver membrane. Biochim Biophys Acta. 1991; 1066(1):77-82.

5. He ZY, Zheng X, Wu XH, et al. Development of glycyrrhetinic acidmodified stealth cationic liposomes for gene delivery. Int J Pharm. 2010; 397(1-2):147-154.

6. Chen J, Jiang H, Wu Y, Li Y, Gao Y. A novel glycyrrhetinic acidmodified oxaliplatin liposome for liver-targeting and in vitro/vivo evaluation. Drug Des Devel Ther. 2015;9:2265-2275.

7. Yamaguchi $\mathrm{H}, \mathrm{Yu} \mathrm{T}$, Kidachi $\mathrm{Y}$, et al. Selective toxicity of glycyrrhetinic acid against tumorigenic $\mathrm{r} / \mathrm{m}$ HM-SFME-1 cells is potentially attributed to downregulation of glutathione. Biochimie. 2011;93(7):1172-1178.

8. Chen Q, Ding H, Zhou J, et al. Novel glycyrrhetinic acid conjugated $\mathrm{pH}$-sensitive liposomes for the delivery of doxorubicin and its antitumor activities. RSC Advance. 2016;6(22):17782-17791.

9. Tian J, Wang L, Wang L, Ke X. A wogonin-loaded glycyrrhetinic acid-modified liposome for hepatic targeting with anti-tumor effects. Drug Deliv. 2014;21(7):553-559.

10. Sun YQ, Dai CM, Zheng Y, Shi SD, Hu HY, Chen DW. Binding effect of fluorescence labeled glycyrrhetinic acid with GA receptors in hepatocellular carcinoma cells. Life Sci. 2017;188:186-191.

11. Langer D, Czarczynska-Goslinska B, Goslinski T. Glycyrrhetinic acid and its derivatives in infectious diseases. Curr Issues Pharm Med Sci. 2016;29(3):118-123.

12. Mahmoud AM, Al Dera HS. $18 \beta$-Glycyrrhetinic acid exerts protective effects against cyclophosphamide-induced hepatotoxicity: potential role of PPAR $\gamma$ and Nrf2 upregulation. Genes Nutr. 2015;10(6):41.

13. Hasan SK, Siddiqi A, Nafees S, et al. Chemopreventive effect of $18 \beta$-glycyrrhetinic acid via modulation of inflammatory markers and induction of apoptosis in human hepatoma cell line (HepG2). Mol Cell Biochem. 2016;416(1-2):169-177.

14. Kuang P, Zhao W, Su W, et al. $18 \beta$-Glycyrrhetinic acid inhibits hepatocellular carcinoma development by reversing hepatic stellate cell-mediated immunosuppression in mice. Int J Cancer. 2013;132(8):1831-1841.

15. Nose M, Ito M, Koide T, Terawaki K, Ogihara Y. The effects of 18 alpha, beta-glycyrrhetinic acid on the hormonal induction of tyrosine aminotransferase in rat primary cultured hepatocytes. Planta Med. 1996;62(5): 410-412.

16. Classen-Houben D, Schuster D, Da Cunha T, et al. Selective inhibition of $11 \beta$-hydroxysteroid dehydrogenase 1 by $18 \alpha$-glycyrrhetinic acid but not 18ß-glycyrrhetinic acid. J Steroid Biochem Mol Biol. 2009; 113(3-5):248-252.
17. Zong L, Qu Y, Xu MY, Dong YW, Lu LG. $18 \alpha$-glycyrrhetinic acid extracted from Glycyrrhiza radix inhibits proliferation and promotes apoptosis of the hepatic stellate cell line. J Digest Dis. 2013;14(6): 328-336.

18. Shetty AV, Thirugnanam S, Dakshinamoorthy G, et al. $18 \alpha$-glycyrrhetinic acid targets prostate cancer cells by down-regulating inflammationrelated genes. Int J Oncol. 2011;39(3):635-640.

19. Ishida S, Sakiya Y, Ichikawa T, Taira Z. Uptake of glycyrrhizin by isolated rat hepatocytes. Biol Pharm Bull. 1993;16(3):293-297.

20. Song H, Sun Y, Xu G, Hou B, Ao G. Synthesis and biological evaluation of novel hydrogen sulfide releasing glycyrrhetic acid derivatives. J Enzyme Inhib Med Chem. 2016;31(6):1457-1463.

21. Su X, Vicker N, Lawrence H, et al. Inhibition of human and rat 11 betahydroxysteroid dehydrogenase type 1 by 18beta-glycyrrhetinic acid derivatives. J Steroid Biochem Mol Biol. 2007;104(3-5):312-320.

22. Lin D, Zhong W, Li J, Zhang B, Song G, Hu T. Involvement of BID translocation in glycyrrhetinic acid and 11-deoxy glycyrrhetinic acidinduced attenuation of gastric cancer growth. Nutr Cancer. 2014;66(3): 463-473.

23. Sun Y, Lu J, Yan D, Shen L, Hu H, Chen D. Cellular uptake mechanism and clearance kinetics of fluorescence-labeled glycyrrhetinic acid and glycyrrhetinic acid-modified liposome in hepatocellular carcinoma cells. Environ Toxicol Pharmacol. 2017;53:46-56.

24. Chu Y, Li D, Luo YF, He XJ, Jiang MY. Preparation and in vitro evaluation of glycyrrhetinic acid-modified curcumin-loaded nanostructured lipid carriers. Molecules. 2014;19(2):2445-2457.

25. Tan C, Xia S, Xue J, Xie J, Feng B, Zhang X. Liposomes as vehicles for lutein: preparation, stability, liposomal membrane dynamics, and structure. J Agric Food Chem. 2013;61(34):8175-8184.

26. Zhang J, Chang D, Yang Y, et al. Systematic investigation on the intracellular trafficking network of polymeric nanoparticles. Nanoscale. 2017;9(9):3269-3282.

27. Roohbakhsh A, Iranshahy M, Iranshahi M. Glycyrrhetinic acid and its derivatives: anti-cancer and cancer chemopreventive properties, mechanisms of action and structure-cytotoxic activity relationship. Curr Med Chem. 2016;23(5):498-517.

28. Mould R, Brown J, Marshall FH, Langmead CJ. Binding kinetics differentiates functional antagonism of orexin-2 receptor ligands. $\mathrm{Br} \mathrm{J}$ Pharmacol. 2014;171(2):351-363.

29. Andar AU, Hood RR, Vreeland WN, Devoe DL, Swaan PW. Microfluidic preparation of liposomes to determine particle size influence on cellular uptake mechanisms. Pharm Res. 2014;31(2):401-413.

30. Ochi MM, Amoabediny G, Rezayat SM, Akbarzadeh A, Ebrahimi B. In vitro co-delivery evaluation of novel pegylated nano-liposomal herbal drugs of silibinin and glycyrrhizic acid (nano-phytosome) to hepatocellular carcinoma cells. Cell J. 2016;18(2):135-148.

31. Ran C, Chen D, Xu M, Du C, Li Q, Jiang Y. A study on characteristic of different sample pretreatment methods to evaluate the entrapment efficiency of liposomes. J Chromatogr B Analyt Technol Biomed Life Sci. 2016;1028:56-62.

32. Awasthi VD, Garcia D, Goins BA, Phillips WT. Circulation and biodistribution profiles of long-circulating PEG-liposomes of various sizes in rabbits. Int J Pharm. 2003;253(1-2):121-132.

33. López O, de la Maza A, Coderch L, López-Iglesias C, Wehrli E, Parra JL. Direct formation of mixed micelles in the solubilization of phospholipid liposomes by Triton X 100. FEBS Lett. 1998;426(3):314-318.

34. Win KY, Feng SS. Effects of particle size and surface coating on cellular uptake of polymeric nanoparticles for oral delivery of anticancer drugs. Biomaterials. 2005;26(15):2713-2722.

35. Tian Q, Wang X, Wang W, Zhang C, Liu Y, Yuan Z. Insight into glycyrrhetinic acid: the role of the hydroxyl group on liver targeting. Int J Pharm. 2010;400(1-2):153-157.

36. Shan L. Near-infrared fluorescence 1,1-dioctadecyl-3,3,3,3-tetramethylindotricarbocyanine iodide (DiR)-labeled macrophages for cell imaging. Molecular Imaging and Contrast Agent Database (MICAD) [Internet]. Bethesda, MD: National Center for Biotechnology Information (US); 2004-2013, 2009. 


\section{Publish your work in this journal}

The International Journal of Nanomedicine is an international, peerreviewed journal focusing on the application of nanotechnology in diagnostics, therapeutics, and drug delivery systems throughout the biomedical field. This journal is indexed on PubMed Central, MedLine, CAS, SciSearch $\AA$, Current Contents $\AA /$ Clinical Medicine,

Journal Citation Reports/Science Edition, EMBase, Scopus and the Elsevier Bibliographic databases. The manuscript management system is completely online and includes a very quick and fair peer-review system, which is all easy to use. Visit http://www.dovepress.com/ testimonials.php to read real quotes from published authors.

Submit your manuscript here: http://www.dovepress.com/international-journal-of-nanomedicine-journal 